\title{
Electron microscopy of undecalcified human bone
}

\author{
R A DODDS, ${ }^{*}$ I SHORE, $\dagger$ J MOSS $\dagger$ From the ${ }^{*}$ Division of Cellular Biology, The Kennedy Institute of \\ Rheumatology, London, and the $\dagger$ Department of Experimental Pathology, Charing Cross and Westminster \\ Hospital Medical School, London
}

SUMMARY An alternative approach for the electron microscopical examination of undecalcified human bone was investigated. The method required bone to be chilled to $-70^{\circ} \mathrm{C}$, sectioned at $10 \mu \mathrm{m}$ in a special bone cryostat, and these sections to be fixed and embedded for ultrathin sectioning. Good preservation of bone cells was seen. The advantages of this method are that it allows numerous particular regions of the $10 \mu \mathrm{m}$ thick sections to be selected under normal light microscopy, and these regions to be then selected for electron microscopy. The $10 \mu \mathrm{m}$ sections allow for excellent penetration of the fixative and thus better preservation of the tissue is more likely.

Electron microscopy permits detailed analysis of fine structure and the way in which this may be changed by disease. It has yielded valuable results when applied to the pathology of soft tissues. Initially, its application to adult bone was less successful because it was common practice to decalcify the bone before embedding and sectioning.

More recently small pieces of fresh bone, perhaps 1 mm thick, have been chipped from the bone by razor blade, and fixed - for example, in buffered gluteraldehyde. 'The trauma that may be induced in the fine structure by this chipping of bone has been ignored. Sections of the embedded fragments have then been cut to facilitate definition of regions of special interest: the embedded block is then trimmed to enable ultrathin sections of the selected area to be prepared.

This procedure is not entirely satisfactory for the following reasons: (i) the removal of chips from the bone usually produces some degree of distortion; (ii) many small chips have to be sectioned to find the region of particular interest; even current fixation procedures may be too slow to ensure full and rapid penetration of up to $1 \mathrm{~mm}$ of dense tissue. For these reasons, an alternative approach has now been investigated. This is based on studies ${ }^{23}$ in which soft tissues were chilled to $-70^{\circ} \mathrm{C}$, sectioned at $10 \mu \mathrm{m}$ in a special cryostat, and fixed and embedded for ultrathin sectioning for electron microscopy. With a range of soft tissues, good preservation of the cells was recorded at a magnification as high as $\times 38000{ }^{2}$ With the demonstration, at the level of the visible light microscope, that unfixed undemineralised bone can be sectioned at, for example, $10 \mu \mathrm{m}$, to yield well preserved sections of bone, ${ }^{4-6}$ it seemed reasonable to test whether such

Accepted for publication 26 August 1987 sections could be used as the starting material for electron microscopy.

\section{Material and methods}

Femoral heads were obtained from patients undergoing total hip replacement. Small blocks of bone (about $1 \times 1 \times 1 \mathrm{~cm})$ were sawn from the femoral head and briefly immersed in $5 \%(\mathrm{w} / \mathrm{v})$ polyvinyl alcohol $(\mathrm{G} 04 /$ 140 Polyviol: Wacker Chemicals), and then chilled in n-hexane (BDH, "low in aromatic hydrocarbons" grade, boiling range $67-70^{\circ} \mathrm{C}$ ) at $-70^{\circ} \mathrm{C}$ by an outer bath of alcohol and crushed solid carbon dioxide. ${ }^{7}$ The chilled tissue was removed with cold forceps after a minute. The bone was attached with 5\% G04 polyvinyl alcohol to solid metal chucks, and cryostat sections $(10 \mu \mathrm{m})$ of the unfixed, undemineralised bone were cut on a Bright's bone cryostat equipped with a Tungsten tipped steel knife (Autoradiographic Products, Cheshire) with the shaft further cooled by the addition of solid carbon dioxide. The cabinet temperature was maintained at -25 to $-30^{\circ} \mathrm{C}$.

The sections were picked up on a square piece of Melinex, and immediately placed into a solution of $3 \%$ glutaraldehyde in $0.1 \mathrm{M}$ phosphate buffer, $(\mathrm{pH}$ $7 \cdot 2$ ) for 30 minutes at $4^{\circ} \mathrm{C}$. Serial sections were also picked up on glass slides and stained for toluidine blue $(0 \cdot 17)$ for additional reference. After fixation the sections were washed twice in $0 \cdot 1 \mathrm{M}$ phosphate buffer (pH 7.2), for five minutes each bath, and post-fixed in $1 \%$ aqueous osmium tetroxide for five minutes. The sections were then washed again in $0.1 \mathrm{M}$ phosphate buffer and dehydrated in a graded series of ethanol. A small volume of $100 \%$ ethanol was left just covering the sections and Spurr resin was then poured on to the sections and left for 10 minutes. The sections were removed and placed in a plastic cap and embedded in 


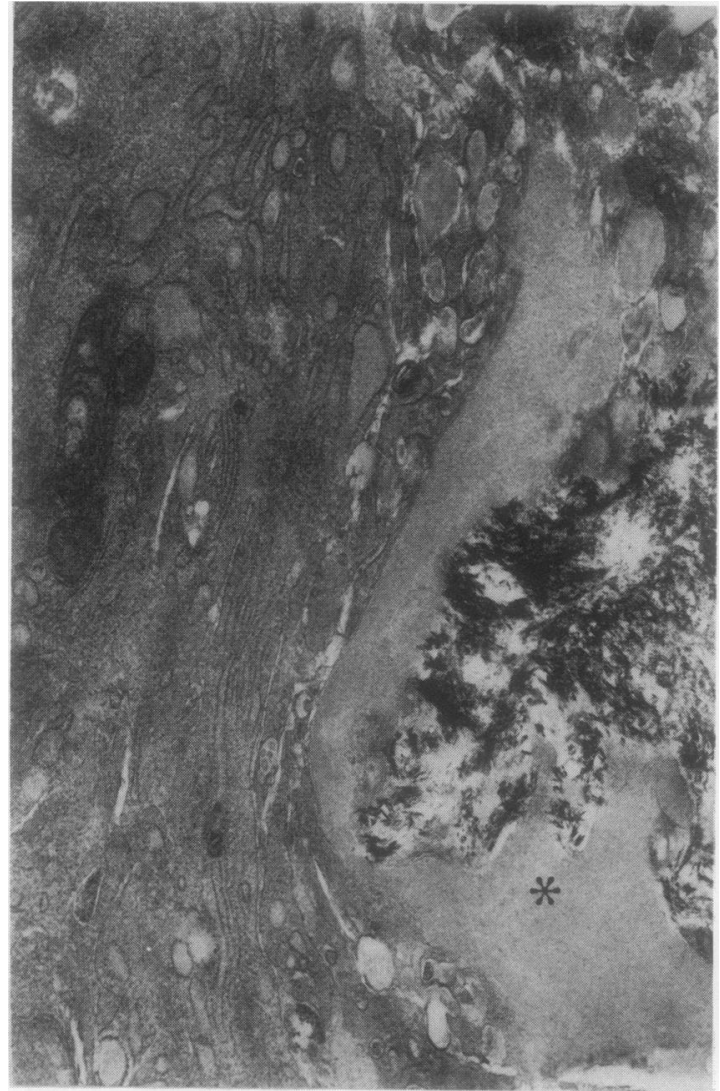

Figure Part of an osteoblast lying on electron dense calcified bone with closely apposed layer of osteoid (*) lying between them. Osteoblast contains rough endoplasmic reticulum and various vesicles, showing good preservation of these membranes with no disruption of cytoplasm.

fresh Spurr resin. Polymerisation was carried out at $60^{\circ} \mathrm{C}$ for 24 hours.

After polymerisation the plastic cap was removed and the Melinex peeled off, leaving the section fully embedded. The embedded sections were examined under low magnification and an area selected for trimming. Semithin sections, 0.5-1.0 $\mu$ m thick, were prepared and stained with toluidine blue $(1 \%)$. Ultrathin silver sections $(60-80 \mathrm{~nm})$ were cut on a Reichert OM U3 Ultramicrotome fitted with a diamond knife. Distilled water was used as the flotation liquid and the sections were picked up on copper grids. These sections were double stained with $1 \%$ aqueous uranyl acetate and Reynolds's lead citrate and examined with a Philips EM 300 electron microscope.

\section{Results}

Good ultrastructural preservation of the bone cells was seen (fig 1). Calcified bone covered by osteoid tissue and lined with active osteoblasts showed extensive rough endoplasmic reticulum, conspicuous Golgi complexes, and mitochondria with clearly preserved cristae. The relation between the cells and the osteoid was clearly visible.

\section{Discussion}

The results indicate that good preservation of bone cells and their associated matrix can be obtained by this procedure. The great advantage of this method is that it allows numerous particular regions of $10 \mu \mathrm{m}$ thick sections to be selected under normal light microscopy and those regions selected for electron microscopy. Because the tissue to be fixed is only 10 $\mu \mathrm{m}$ thick, better preservation with the slowly penetrating fixative is more likely. Moreover, electron histochemical procedures can be applied to the $10 \mu \mathrm{m}$ sections for high resolution definition of biochemical activities. $^{8}$

\section{References}

1 Fornasier VL. Transmission electron microscopy studies of osteoid maturation. Metabolic Bone Disease and Related Research 1980;2:103-8.

2 Altman FP, Barnett RJ. The ultrastructural localisation of enzyme activity in unfixed sections. Histochemistry 1975;44:179-83.

3 Zoller LC, Weisz J. The demonstration of regional differences in lysosome membrane permeability in the membrana granulosa of Graafian follicles in cryostat sections of the rat ovary: a quantitative cytochemical study. Endocrinology 1980;106: 871-7.

4 Johnstone $\mathrm{JJ}$. The routine sectioning of undecalcified bone for cytochemical studies. Histochem J 1979;11:359-65.

5 Dodds RA, Catterall A, Bitensky L, Chayen J. Effects on fracture healing of an antagonist of the vitamin $\mathrm{K}$ cycle. Calcif Tiss Int 1984;36:233-8.

6 Dodds RA, Catterall A, Bitensky L, Chayen J. Abnormalities in fracture healing induced by vitamin $\mathrm{B}_{6}$-deficiency in rats. Bone 1986;7:489-95.

7 Chayen J, Bitensky L, Butcher RG. Practical histochemistry. London: John Wiley \& Sons, 1973.

8 Shnitka TK, Seligman AM. Ultrastructural localization of enzymes. Ann Rev Biochem 1971;40:375-96.

Requests for reprints to: Dr R A Dodds, Division of Cellular Biology, The Mathilda and Terence Kennedy Institute of Rheumatology, 6 Bute Gardens, Hammersmith, London W6 7DW, England. 